\title{
Integrated Business Startup (IBS) Innovation Design for Cooperatives And Smes South Sumatera Province Based On Android
}

\author{
Adelin $^{1}$, Febrianty ${ }^{2}$, Hendra Hadiwijaya ${ }^{3}$, D. Tri Octafian ${ }^{4}$, Guntoro Barovih ${ }^{5}$ \\ \{febrianty@palcomtech.ac.id\} \\ ${ }^{2,3}$ Palcomtech Polytechnic, Palembang, Indonesia \\ 2,4,5STMIK Palcomtech, Palembang, Indonesia
}

\begin{abstract}
The development of a one-stop startup system that was initiated directly by the Provincial Government, which can increase tourism promotion, cooperatives, and SMEs in South Sumatera Province is urgently needed. The system is used in 13 districts and 4 cities in South Sumatera Province. The purpose of this study is to recommend an innovative design for a new model of startup system that integrates cooperatives and SMEs as well as Android-based tourism into an Android-based marketplace. System Development with Rapid Application Development (RAD) Method, with 3 major phases involving users and analysts in the assessment, design, and implementation process. The results of this study recommend an android-based startup application called the IBSSumsel Application. The IBSSumsel application can be a medium for promoting potential products of the Office of Cooperatives and SMEs in South Sumatera Province. The IBSSumsel application can integrate the tourism sector, cooperatives, and SMEs with the community so that these products can be better known to the community and provide convenience in accessing these products. In addition, the IBSSumsel application can be a medium for the Office of cooperatives and SMEs in monitoring the development and performance of cooperative and SME coaching. Its implementation will be able to assist local governments in realizing independent and competitive Cooperatives and SMEs and of course able to face the challenges of the 4.0 era.
\end{abstract}

Keywords: IBS, Android, Startup, Cooperative, SME, Tourism, South Sumatera

\section{Introduction}

Small and Medium Enterprises (SMEs) and startups are widely recognized as having played an important and substantial role in the Indonesian economy. Therefore, ecosystems and standardization are needed that can better facilitate the growth and development of SMEs and startups. Industrial Revolution 4.0, also demands cooperatives and SMEs ready to adapt and transform with the development of digital technology, Big Data, IoT, robotics technology, and so on. Standards are an integral part of maintaining the fast pace of new innovations in ICT and other technology-dependent industrial sectors. Standardization provides broad and profitable competitive technology transfer, access to markets, and complementary coordination of technologies and products and services that adopt these technologies. Therefore, for SMEs and startups to remain relevant and connected with 
advanced technology, the global standardization system must ensure that it responds to the needs of these entities (Vries, et al., 2009), and supports the active participation of SMEs and startups in the design and implementation of standards ICTs (and others) that will prop up the Internet of Things and the $5 \mathrm{G}$ revolution. The role of ecosystem creation and standardization can be carried out by the Office of Cooperatives and SMEs as policymakers.

Likewise with cooperatives, if cooperatives still run a "monotonous" pattern that does not utilize technological developments optimally and is ready to transform in the Industrial Revolution Era 4.0 then it is not possible if cooperatives will be abandoned. It is well known that IT capability constraints are a factor in IT adoption decisions and subsequent use, and especially for SMEs. In general, increasing the benefits of IT / IS investment is a challenge for SMEs given their limited technical capabilities and human resources (Ada, 2009). However, this can be overcome by using IT/IS together or integrated. The result is the creation of a sustainable marketing channel, an increase in short-term revenue and long-term sales, a reduction in advertising costs of up to $70 \%$, a reduction in overall marketing costs, the creation of competitive advantages, ease of promotion across social media platforms, increased brand and product popularity, organizational recognition or company to the community (Febrianty, et al., 2019). The study of Chin et al. explains how contingency factors (social networking relationships and strategic flexibility) facilitate entrepreneurial companies to break down institutional barriers and get the most out of EO. The results achieved provide new knowledge about how Chinese global startup OEMs use EO to reverse internationalization, in response to calls to uncover the heterogeneous characteristics of the EO sub-dimensions and to the more contextually attached treatment of EO performance associations (Chin , et al., 2016). This shows that how Chinese OEMs use EO in their global startups. Along with this trend, more and more export-driven global startup OEMs have come into existence, becoming a prevalent and typical type of entrepreneurial firms in China for the past three decades (Chin, et al., 2015). Evidence also manifests that these global startup OEMs that compete abroad at early age have learned a variety of advanced knowledge and technology through collaboration with FDIs, whereby some ambitious ones even further upgraded to engage in original brand manufacturing (OBM) (Chin, et al., 2015) (Child \& Rodrigues, 2005).

The growth of startups in Indonesia is getting brighter, this momentum needs to be utilized as well as possible in order to increase competitiveness. This needs to be a concern of local governments, especially the Office of Cooperatives and SMEs, to take part in a large part of the development of startups. The role of local governments, especially in the Office of Cooperatives and SMEs can be optimized through the initiation movement to integrate Cooperatives and SMEs into the startup system so that the results obtained are more optimal and have an impact especially on the growth of cooperatives and SMEs.

South Sumatera Province has a huge potential in the development of startups but the available resources are still limited so that the potential/excellence that is not maximally exposed. Based on BPS data for 2019 for January, the number of foreign tourists visiting South Sumatera through the entrance of Sultan Mahmud Badaruddin II Airport in Palembang in January 2019 recorded 811 visits, a decrease of 43.33 percent compared to December 2018 (https: //sumsel.bps.go.id). The data indicate that tourism promotion is still limited, whereas if synergizing and utilizing startups, the number of tourists can increase each year.

On the other hand growth in the tourism sector has a direct and indirect impact on the turnover of SMEs. Because of the interconnection between sectors, because the SME sector also provides products and or services needed by tourists and even many of the SMEs that provide icons and all local wisdom that support tourism. This research will recommend an 
innovative design for a new model of a startup system that integrates cooperatives and SMEs as well as Android-based tourism into an Android-based marketplace.

\section{Methods}

\subsection{Integrated Startup}

In the early 2000s, we also started to recognize the term Startup, which is defined as a startup company that has not been operating for a long time and runs its business using mobile or desktop-based software and websites. High-speed net connectivity brings many choices of users on social media which indicates that sellers need to be more focused and targeted in virtual advertising and promote instrumentation for effective though inexperienced markets and markets to realize different structural desires (Junaidi, et al., 2020).

This shows that startups must incorporate the needs of SMEs to broadly promote their business products. In addition, SME entrepreneurs are also easy to use and are aimed at their business segments or operators in the same category and are encouraged by the provincial government. This will have an extraordinary effect on increasing the competitiveness of SMEs. Therefore, most startups that are developing now facilitate the marketing of products of middle and upper-class business people.

The results showed that direct Perceived Usefulness and perceived enjoyment as well as Intellectual Capital had a positive effect on the Intention to Continue Using Social Media Marketing. Conversely, perceived risk or cost has a negative influence on the intention to continue using social media marketing. Intention to Continue Using Social Media Marketing has a positive effect on MSME turnover (Febrianty, et al., 2019).

\subsection{System Development with RAD Method}

Rapid Application Development (RAD) is one of the methods used for system development. This method can shorten system development time. RAD is a set of methods developed to overcome the weaknesses of traditional system development methods, such as the waterfall model and its variants (Dennis, et al., 2014). This method is the method used in the rapid application development cycle and also provides good quality software compared to traditional software engineering approaches. Through a rapid application development process, organizations can reduce software development costs and maintenance costs (Naz \& Khan, 2015).

RAD consists of 3 (three) major phases involving users and analysts in the assessment, design, and implementation process. The three phases are (Kendall \& Kendall, 2010):

a) Requirement Planning Phase

In this phase, users and analysts meet to identify application or system objectives and to identify information needs that arise based on these objectives. This phase requires intense involvement from both parties.

b) Workshop Design Phase

This phase is a design-and-repair phase characterized as a workshop, where participants are involved intensively and actively. During the Design Workshop phase, the user responds to the actual prototype being worked on, while the analyst makes improvements to the modules that have been designed based on the user's response. 
c) Implementation Phase (Implementation)

In the design phase of the workshop, the analyst works intensively with users to design business processes or non-technical aspects of the system. If both of these aspects have been agreed upon and the system has been built and improved, it will enter the implementation phase where the new system or part of the system is tested and then introduced to the organization.

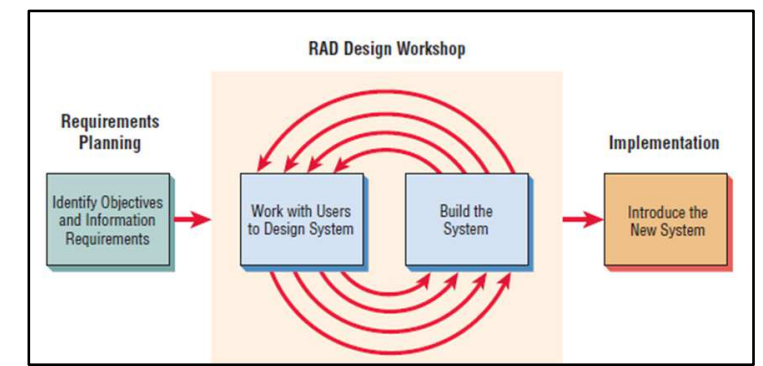

Fig.1. Stages of the RAD Method (Kendall \& Kendall, 2010)

\subsection{Android}

Android is a lightweight operating system managed by Google, based on the Linux kernel and designed for mobile devices, especially touch screens such as smartphones and tablet computers (Liang, et al., 2020). This application is free for all open source under the Apache license. Android middleware, libraries, and APIs are coded in the C programming language. The first version of Android was released in 2005 by Google and then continues to grow rapidly until now (Ayyasamy , 2015). Among other operating systems, Android has several advantages, namely: Android is open source so that it can be developed by anyone, has a lot of manufacturer support so that it can be accessed by almost all brands of smartphones, and supports all Google services.

\subsection{Flutter}

Flutter is an SDK application for building applications with high performance and accuracy for IOS, Android, Web (beta), and desktop from a single code base. Flutter allows developers to build applications that are high-performance and feel natural on different platforms. Flutter is able to embrace cross-platform differences in terms of scrolling behavior, typography, icons, and much more (Zuze, 2020).

\subsection{Unified Model Language (UML)}

UML is a language-oriented model of computer systems that are very complicated and with prescribed structures, it is also possible to model non-computer systems such as workflows, organizational structure design, hardware design, and automation applications (Garces, et al., 2019). UML is an applicative modeling language that is well-defined, easily expressed, capable, and universal. UML integrates new ideas, methods, and technology in the field of software engineering. Its scope is not only to support object-oriented analysis and design but also to support the entire software development process starting from needs analysis (Tang, 2019).

UML as a visual modeling language, its main manifestation is a graphical representation of the model. The UML specification strictly defines symbols from various elements of the model, and also includes abstract and semantic grammars from these models and symbols. By 
using the diagrams in UML, the application developed is easier to understand. UML diagrams that are often used include use case diagrams, class diagrams, activity diagrams, sequence diagrams, and others. Each use case must provide some observable and valuable results for the actors or other stakeholders of the system (Peng, 2019).

\section{Result and Discussion}

\subsection{Requirements Analysis}

a) An application that can integrate cooperative managers and SME operators is needed by the local government in this case the Office of Cooperatives and SMEs.

b) The application will be built based on mobile so it can be accessed anytime and anywhere.

\subsection{Use Case diagram}

Use case diagrams are diagrams that illustrate system behavior. Use case diagrams are used to illustrate a series of actions (use cases) where several systems must or can be carried out in collaboration with one or more external users of the system (actors) (https://www.umldiagrams.org/, 2020).

\subsubsection{Actor Use Case}

This application consists of 4 actors namely "admin", "SMEs", "Cunsumer", and "a delivery agent". Descriptions of each actor can be seen in table 1 .

Table 1. Actor Description

\begin{tabular}{|c|c|c|}
\hline No. & Aktor & Description \\
\hline 1 & Admin & $\begin{array}{l}\text { Admin on this application is from the admin who came from the } \\
\text { Department of Cooperatives and SMEs of South Sumatera Province. } \\
\text { Admin actor is a person who has access rights to manage seller accounts, } \\
\text { manage travel information, manage Event information and manage } \\
\text { disability flagship products }\end{array}$ \\
\hline 2 & SMEs & $\begin{array}{l}\text { The UKM actor is an actor who comes from UKM which is under the } \\
\text { management of the South Sumatera Province Cooperative and UKM } \\
\text { Office and under the management of the Alisa Khadijah Association. SME } \\
\text { Actors have access rights to manage products sold, view orders, manage } \\
\text { orders, and manage shipping orders. }\end{array}$ \\
\hline 3 & Consumer & $\begin{array}{l}\text { An actor who has access rights to view tourism information, order tourism } \\
\text { services, view cooperative product information, order cooperative } \\
\text { products, view Leading Disability Products, order superior disability } \\
\text { products, view SME products, order SME products, view souvenir } \\
\text { information, order souvenirs, view culinary information, order culinary, } \\
\text { rent a car, order a tour guide, make payments and view Event information }\end{array}$ \\
\hline 4 & $\begin{array}{l}\text { Delivery } \\
\text { Agent }\end{array}$ & Is an actor who has access to manage order shipments \\
\hline
\end{tabular}

The use case diagrams in this study are illustrated in Figure 2. 


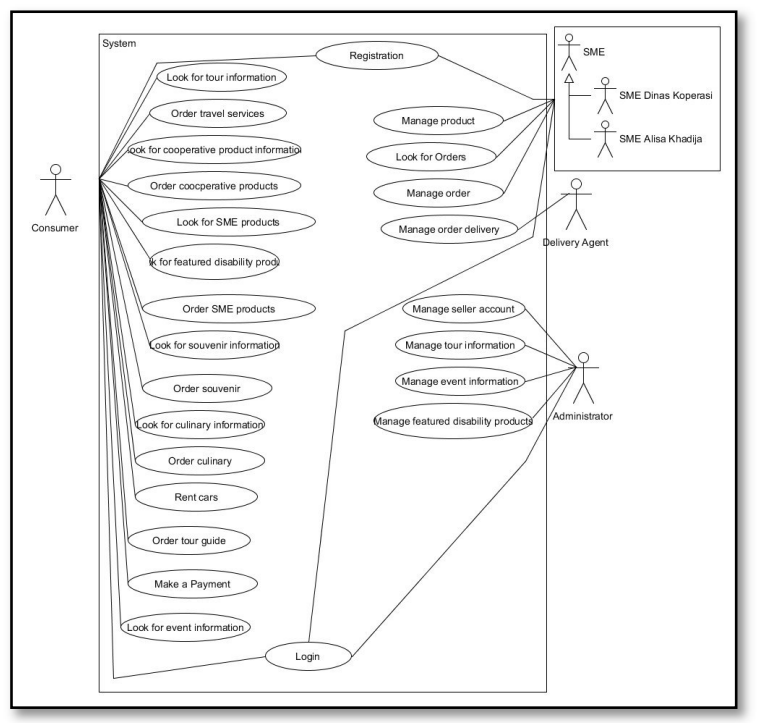

Fig. 2. Use Case Diagram

Figure 1 shows the functional requirements of the IBS application, which consists of 4 actors and 26 use cases. Then each use case scenario is made that will explain the sequence of actions and reactions between the actor and the system.

The use case scenario for managing SME data can be seen in table 2 .

Table 2. Use case scenarios managing SME data

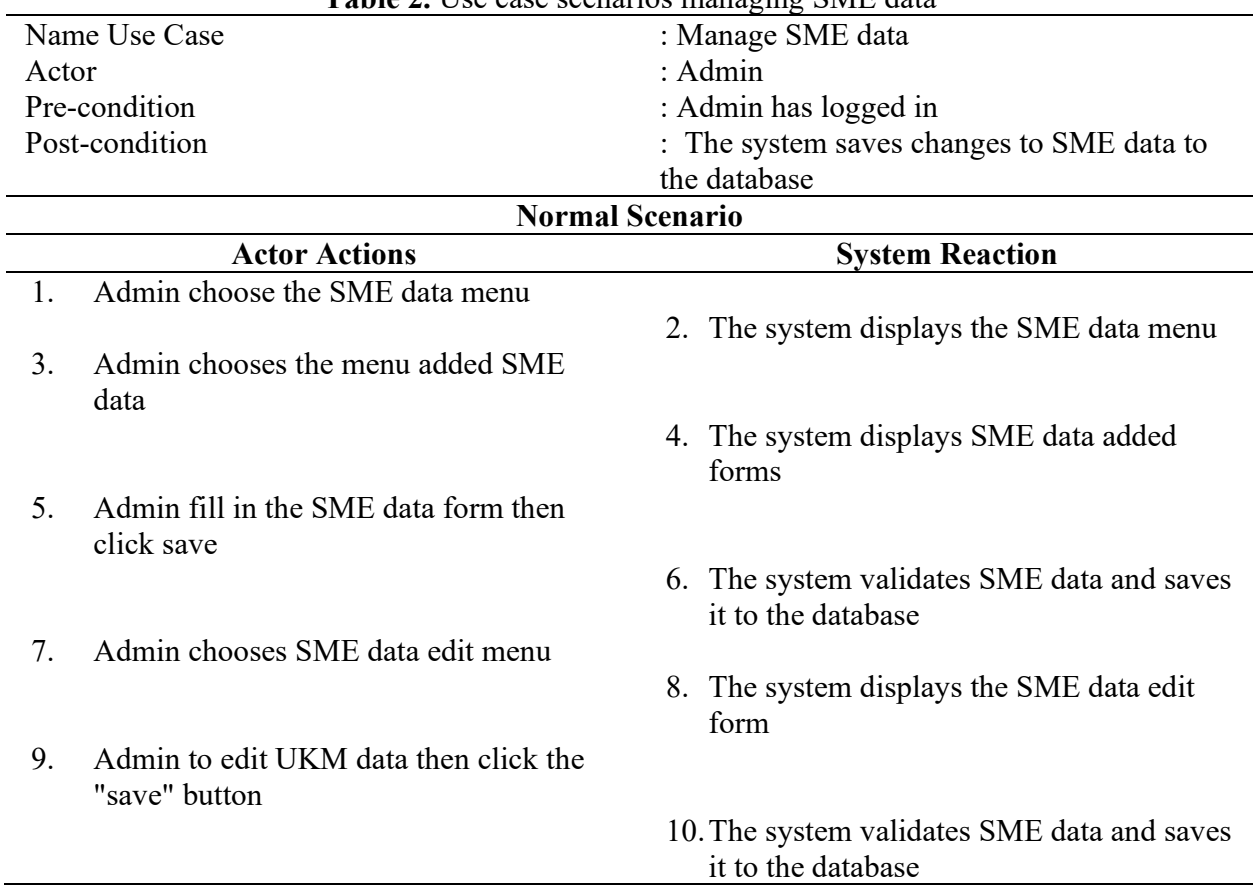


11. Admin chooses to delete SME data

12. The system displays confirmation of the deletion

13. Admin confirms delete SME data by clicking the "yes" button

14. The system erases SME data from the database

Table 2 shows the sequence of actions of admin actors and system reactions in the SME data management process. The use case scenario of managing cooperative data can be seen in table 3. Table 3 explains how the actions of actors in this case the system admin and the reaction of the system in the process of managing cooperative data.

Table 3. Use case scenarios managing cooperative data

\begin{tabular}{ll}
\hline Name Use Case & $:$ Manage cooperative data \\
Actor & $:$ Admin \\
Pre-condition & $:$ Admin has logged in \\
Post-condition & $:$ The system saves cooperative data \\
& changes to the database \\
\hline
\end{tabular}

\begin{tabular}{lll}
\hline \multicolumn{2}{c}{ Normal Scenario } \\
\hline Actor Actions & System Reaction \\
\hline $\begin{array}{lll}\text { 1. Admin chooses cooperative data menu } \\
\end{array}$ & $\begin{array}{ll}\text { 2. } \\
\text { The system displays a cooperative data } \\
\text { menu }\end{array}$
\end{tabular}

3. Admin chooses menu added data cooperative

4. The system displays a form added cooperative data

5. Admin fill in the cooperative data form then click save

6. The system validates cooperative data and saves it to the database

7. Admin chooses cooperative edit menu

8. The system displays a cooperative edit form

9. Admin edit the cooperative then click the "save" button

10. The system validates cooperative data and saves it to the database

11. Admin chooses to delete cooperative

13. Admin confirms delete cooperatives by clicking the "yes" button

12. The system displays confirmation of the deletion

14. The system removes cooperative data from the database

Scenarios for managing SME product data are explained in table 4 . Table 4 describes the sequence of SME actor action scenarios and system reactions in the process of managing SME products. 
Table 4. Use case scenarios for managing SME product data

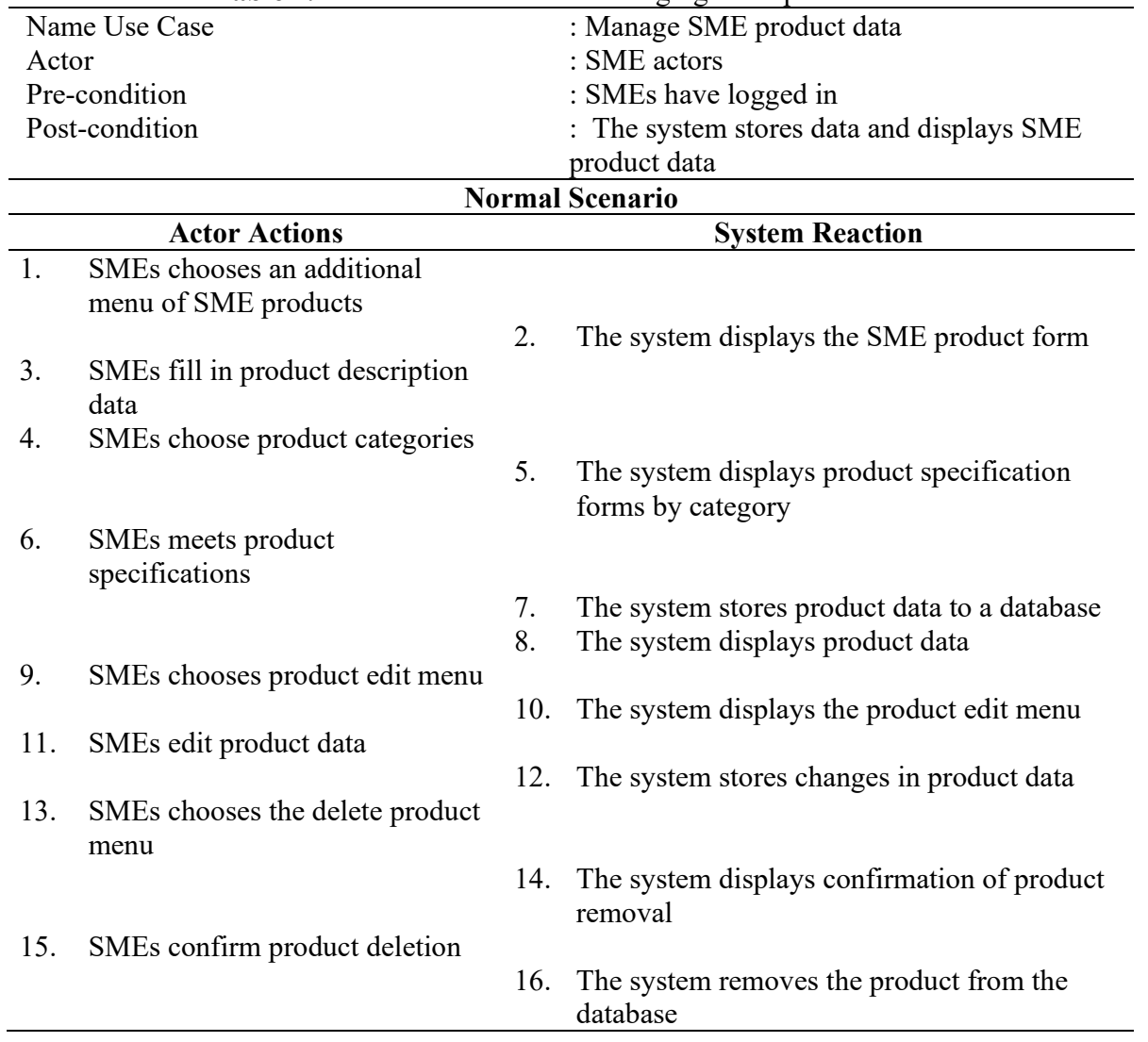

\subsubsection{Activity Diagram}

The activity diagram illustrates the dynamic behavior of system functions and the sequence of relationships between activities, which shows the entire workflow of the system (Xia, et al., 2019). The activity diagram of managing SME products can be seen in Figure 3. Figure 3 shows the activities of SME actors in managing SME products in the system. 


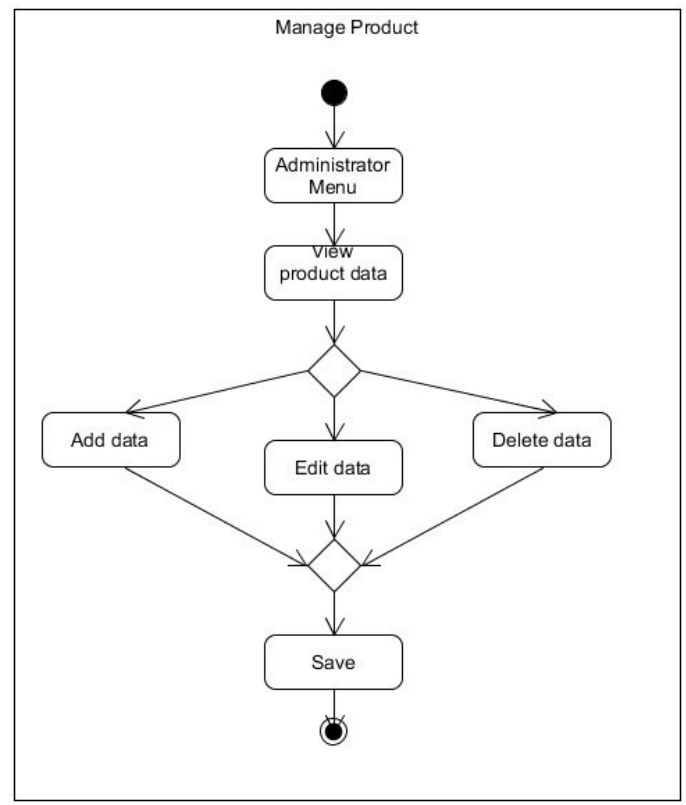

Fig.3. Activity Diagram of managing SME products

The activity diagram ordering SME products can be seen in Figure 4. Figure 4 shows consumer activity when ordering SME products.

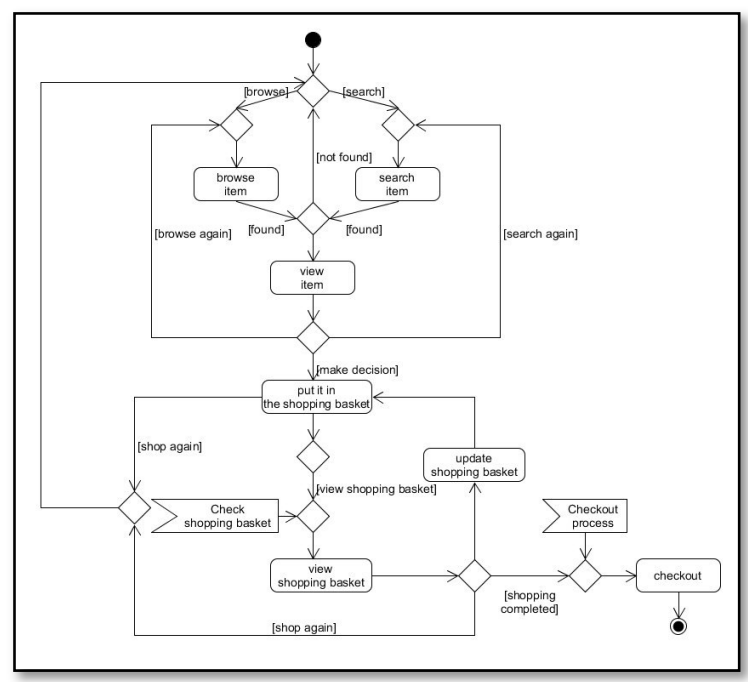

Fig.4. Activity diagram of ordering SME products

Activity Diagram of managing orders placed by SME actors can be seen in Figure 5. 


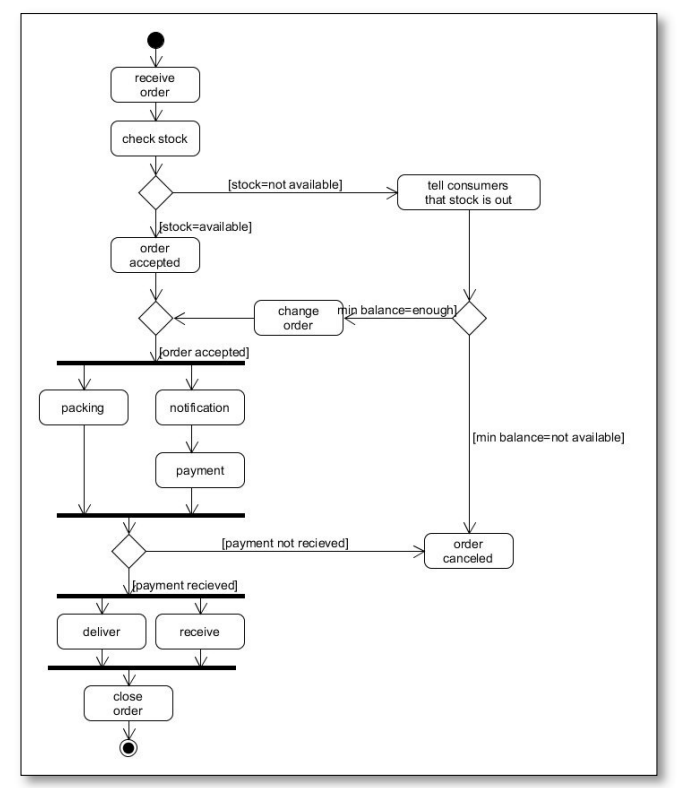

Fig.5. Activity diagram of managing orders

Figure 5 shows the activities of SME actors in managing orders. This activity begins when there is an order for SME products from consumers.

\subsection{Results}

The Integrated Business Startup (IBS) application is made with the android platform and is named IBSSumsel. The main page of this application can be seen in Figure 6.

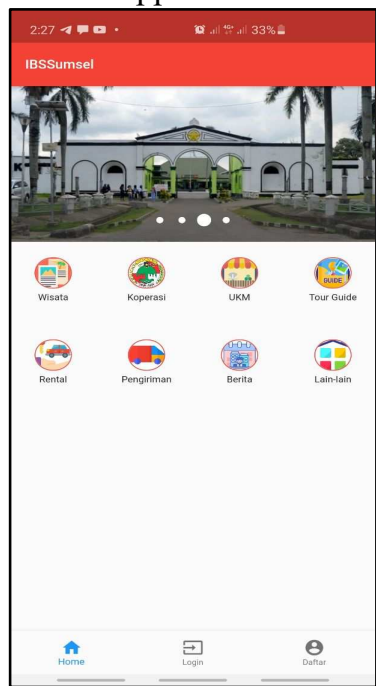

Fig.6. IBSSumsel home page

Because of the information presented in the IBSSumsel Application in Indonesian. This main page consists of 8 menus: "Wisata", "Koperasi", "UKM", "Tour Guide", "Rental", 
"Pengiriman", "Berita" and "Lain-lain". The "Wisata" menu contains the names of tourist attractions in the province of South Sumatera. This page aims to introduce tourists to what tourist objects can be visited while in the province of South Sumatera. This menu will be linked to the Tour Guide Menu if users need tour guide services to the tourist sites.

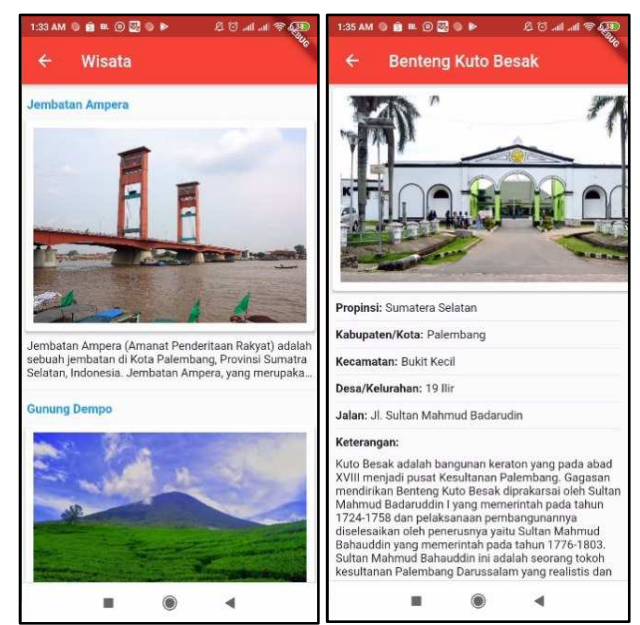

Fig.7. "Wisata" Menu Page

The Cooperative menu contains a database of cooperatives registered with the South Sumatera Cooperative Service. Where this menu consists of several sub-menus, namely Production Cooperatives, Consumption Cooperatives, Savings and Credit Cooperatives, and Business Multipurpose Cooperatives. The "UKM" menu contains UKM products registered with the South Sumatera Cooperative Service. This menu has sub-menus, namely: culinary, souvenirs, and regional superior products. Through this menu, visitors can see superior products from SMEs and can order products. Transactions can be done through this application, making it easier for users to get the desired SME products.

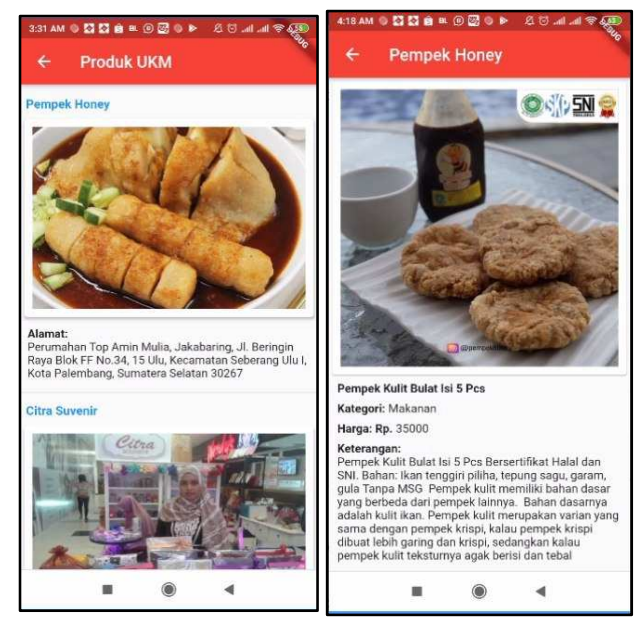

Fig.8. "UKM" Menu Page 
The "Berita" menu contains news related to the South Sumatera Cooperative Service including activities or events related to tourism and SMEs in the province of South Sumatera.

\section{Conclusion}

This design innovation recommends an Android-based startup application called the IBSSumsel Application. The IBSSumsel application can be a medium for promoting potential products of the Office of Cooperatives and SMEs in South Sumatera Province. The IBSSumsel application can integrate the tourism sector, cooperatives, and SMEs with the community so that these products can be better known to the community and provide convenience in accessing these products. In addition, the IBSSumsel application can be a medium for the Office of cooperatives and SMEs in monitoring the development and performance of cooperative and SME coaching.

\section{REFERENCES}

[1] Ada, S., 2009. SMEs' e-commerce adoption: perspectives from Denmark and Australia. Journal of Enterprise Information Management, Volume 22, p. 152-162.

[2] Ayyasamy , A., 2015. Survey on Android Application Advancement and Security. s.1., Seventh International Conference on Advanced Computing(ICoAC), December 2015.

[3] Child , J. \& Rodrigues, S., 2005. The Internationalization of Chinese firms:A Case for theoretical extension?. Management and Organization Review, Volume 13, p. 381-410.

[4] Chin, T., Liu, R.-h. \& Yang, X., 2015. Reverse internationalization in Chinese firms:A study of how global startup OEMs seek to compete domestically.. Asia Pacific Business Review, Volume 22 (2), p. 201-219.

[5] Chin, T. et al., 2016. EO-Performance relationships in Reverse Internationalization by Chinese Global Startup OEMs: Social Networks and Strategic Flexibility.. PLOS ONE, 11(9): e0162175.(https://doi.org/10.1371/journal.pone.0162175).

[6] Dennis, A., Wixom, B. H. \& R.M., R., 2014. Systems Analysis \& Design. 6th ed. ed. US: John Wiley and Sons Inc..

[7] Febrianty, F. et al., 2019. The perception on technology acceptance to the behaviors on the use of social media for marketing and its implications on the turnover of creative industry MSMEs in villages.. Journal of Physics: Conference Series, , Issue Volume 1175, conference 1. https://iopscience.iop.org/article/10.1088/1742-6596/1175/1/012216/pdf..

[8] Garces, E. F. M., Mafla, G. M. \& Reyes, F., 2019. Analysis, Review and Development of a Conceptual Model, based on Class Diagrams as a Component of UML, Focused on Industrial Automation. International Journal of Robotics and Automation, Issue vol. 4, pp. 6-10.

[9] https://www.uml-diagrams.org/, 2020. UML Use Case Diagrams. [Online] Available at: https://www.uml-diagrams.org/use-case-diagrams.html. [Accessed 20 March 2020].

[10] Junaidi, J. et al., 2020. Impact of Digital Marketing on the Growth of E-Service Sales. International Journal of Psychosocial Rehabilitation, Vol 24(1), pp. 1219-1229.

[11] Kendall, K. E. \& Kendall, J. E., 2010. Systems Analysis and Design. 8th ed. ed. New Jersey: Prentice Hall.

[12] Liang, Y., Li, Q. \& Xue, C. J., 2020. Mismatched memory management of android smartphones.

Available at: https://www.usenix.org/system/files/hotstorage19-paper-liang.pdf

[Online]

[14] Naz, R. \& Khan, M. N. A., 2015. Rapid applications development techniques: A critical review. International Journal of Software Engineering and Its Applications, Issue vol. 9, no. 11 , pp. $163-176$. 
[15] Peng, Y., 2019. Overview of Object-Oriented System Development Method and UML Modeling Language. Francis Academic Press, UK, 9th International Conference on Information and Social Science (ICISS 2019).

[16] Tang, H., 2019. The Establishment of Network Teaching Platform Model based. Advances in Social Science, Education and Humanities Research, Issue vol. 342, no. Ielss, pp. 59-63.

[17] Vries, R. E. d. et al., 2009. The Content and Dimensionality of Communication Styles. Communication Research, Issue January. Vol 36(2):178-206..

[18] Xia, H., Jiao, J. \& Dong, J., 2019. Extend UML Based Timeliness Modeling Approach for Complex System. s.1., Proceedings of the 2018 International Conference on Mathematics, Modeling, Simulation and Statistics Application (MMSSA 2018).

][19] Zuze, D., 2020. An Overview of Flutter. 28 May, pp. https://softwareengineeringdaily.com/2018/10/08/an-overview-of-flutter/. 